\title{
Perceived and geographic food access and food security status among households with children
}

\author{
Xiaoguang $\mathrm{Ma}^{1,2}$, Angela D Liese ${ }^{1,3, *}$, Bethany A Bell ${ }^{1,4}$, Lauren Martini ${ }^{1,3}$, \\ James Hibbert ${ }^{1}$, Carrie Draper ${ }^{1}$, Michael P Burke ${ }^{5}$ and Sonya J Jones ${ }^{1,6}$ \\ ${ }^{1}$ Center for Research in Nutrition and Health Disparities, Arnold School of Public Health, University of South \\ Carolina, 921 Assembly Street, Columbia, SC 29208, USA: ${ }^{2}$ Department of Nutrition and Food Hygiene, School of \\ Public Health, Zhejiang University, Hangzhou, Zhejiang, People's Republic of China: ${ }^{3}$ Department of Epidemiology \\ and Biostatistics, Arnold School of Public Health, University of South Carolina, Columbia, SC, USA: ${ }^{4}$ College of \\ Social Work, University of South Carolina, Columbia, SC, USA: ${ }^{5}$ US Department of Agriculture, Food and Nutrition \\ Service, Alexandria, VA, USA: ${ }^{6}$ Department of Health Promotion, Education, and Behavior, Arnold School of Public \\ Health, University of South Carolina, Columbia, SC, USA
}

Submitted 23 September 2015: Final revision received 16 March 2016: Accepted 24 March 2016: First published online 2 May 2016

\begin{abstract}
Objective: To examine the association of both perceived and geographic neighbourhood food access with food security status among households with children.

Design: This was a cross-sectional study in which participants' perceptions of neighbourhood food access were assessed by a standard survey instrument, and geographic food access was evaluated by distance to the nearest supermarket. Multinomial logistic regression models were used to examine the associations

Subjects: The Midlands Family Study included 544 households with children in eight counties in South Carolina, USA. Food security status among participants was classified into three categories: food secure (FS), food insecure (FI) and very low food security among children (VLFS-C).

Results: Compared with FS households, VLFS-C households had lower odds of reporting easy access to adequate food shopping. VLFS-C households also had lower odds of reporting neighbourhood access to affordable fruits and vegetables compared with FS households and reported worse selection of fruits and vegetables, quality of fruits and vegetables, and selection of low-fat products. FI households had lower odds of reporting fewer opportunities to purchase fast food. None of the geographic access measures was significantly associated with food security status.

Conclusions: Caregivers with children who experienced hunger perceived that they had less access to healthy affordable food in their community, even though grocery stores were present. Approaches to improve perceived access to healthy affordable food should be considered as part of the overall approach to improving food security and eliminating child hunger.
\end{abstract}

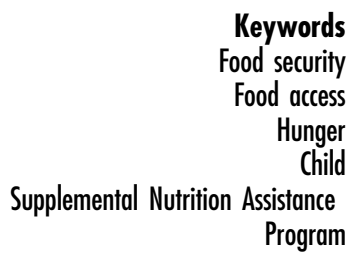

Keywords

Food access

Hunger

Child

Program
In 2013 , approximately $9.9 \%$ (3.8 million) of households with children experienced food insecurity in both adults and children in the USA ${ }^{(1)}$. Food insecurity is defined as limited access to adequate food due to lack of money and other resources ${ }^{(1)}$. The most severe form of food insecurity in children, very low food security in children (VLFS-C; which entails caregivers reporting that 'children were hungry, skipped a meal, or did not eat for a whole day because there was not enough money for food'), was experienced by children in $0.9 \%$ of US households with children in $2013^{(1)}$.
Previous research has shown that few children in foodinsecure (FI) (especially VLFS-C) households meet the recommendations for dietary intake, including nutrients such as $\mathrm{Ca}$, dietary fibre and $\mathrm{Na}^{(2-5)}$. Given that the food environment has been shown to be associated with dietary intake $^{(6-13)}$, it is possible that the neighbourhood food environment may exacerbate poor dietary intake associated with food insecurity among households with children by: (i) providing insufficient availability and accessibility of low-energy nutritious foods and excess availability and accessibility of energy-dense foods ${ }^{(6,7,14)}$; 
(ii) pricing nutritious foods higher ${ }^{(15-17)}$; and (iii) demanding an extra transportation burden for low-income populations $^{(18,19)}$.

A neighbourhood food environment can be characterized by different measures and instruments, including geographic information system (GIS)-based measurements and selfreported individual perceptions of the food environment. GIS has been used to characterize the food environment by relying on geographic data about the presence of retail food outlets and residents; GIS measures include population number and density in an area and the distance to the nearest food outlet, among other factors ${ }^{(20)}$. Few studies have examined the association between GIS-based food environment measures and food security status, and the findings that do exist have been inconsistent ${ }^{(21-25)}$. Kirkpatrick and Tarasuk found that food security status was not associated with proximity to food retail or community food programmes in Canadian families ${ }^{(21)}$. Another Canadian study found that FI respondents lived significantly closer to nutritious food sources and grocery stores than food-secure (FS) respondents ${ }^{(22)}$. Carter et al. reported a null relationship between food security status and residence location of children in their study ${ }^{(23)}$. Two studies have claimed that easy access to less healthful foods (i.e. fast foods) in the household is associated with food insecurity among children ${ }^{(24,25)}$.

When policies attempting to improve access to healthy foods have focused on improving proximity to the geographic locations of healthy food stores, the importance of considering self-reported perceptions of food access has been emphasized ${ }^{(26)}$, because individual perceptions capture different dimensions of access compared with GIS-based features of the food environment $^{(7,27,28)}$. However, few studies have focused on caregivers' perceptions of the food environment and household food security status, especially in households with children. Sharkey et al. investigated parents' perceived neighbourhood food environments in Mexicanorigin households in Texas border colonias with VLFS-C compared with households without child hunger, and found that VLFS-C households reported little variety of foods, few grocery stores and high food prices in their neighbourhood ${ }^{(29)}$. Based on three waves of the Southeastern Pennsylvania Household Health Survey, Mayer et al. found that self-reported easy access to fruits and vegetables and availability of good-quality foods in neighbourhoods were associated with lower odds of being $\mathrm{FI}^{(30)}$. However, none of the previous research utilized comprehensive standard questionnaires on perceived food access and adequately adjusted for confounders.

In the present study, we examined the association between perceived and GIS-based food access and food security status in a sample of rural and urban predominantly African-American households with children in South Carolina, USA, with extensive information on attributes that may confound relationships between access and food security.

\section{Methods}

\section{Study population}

The study sample was derived from the Midlands Family Study of the household and community conditions associated with very low food security in children. The families in that study were recruited from a contiguous eight-county region in South Carolina, including one metropolitan county and seven surrounding rural counties. To recruit participants, a sampling framework of traditional food sources (e.g. grocery stores, farmers' markets and day-care providers) and emergency food sources (e.g. food pantries) was constructed, resulting in a list of 1646 potential recruitment sites generated through online searches or by contacting the appropriate agency (e.g. obtaining lists of summer feeding sites from the administering agency). The sites were stratified by urban ( $n$ 776) and non-urban ( $n$ 870) location. Then forty urban and forty non-urban sites were randomly sampled from the list. The sites were replaced as necessary if the site refused to participate, was unreachable or yielded no participants. In total, 249 urban sites and 178 non-urban sites were included.

At each sampled site, the clients or customers were invited to participate in a screening survey. The screened participants were invited to complete the household caregiver survey if they: (i) had a child under 18 years of age living in the household at least $50 \%$ of the time; (ii) resided in one of the eight study counties; (iii) had a total annual household income below \$US 100 000; and (iv) fell into one of the three food security status categories, namely FS, FI or VLFS-C. The income threshold was chosen because it is close to the value corresponding to $300 \%$ of the poverty line for a family with four children (\$US 97710). This value (300\% of the poverty line) is currently being advocated as a new cut-off for participation in food assistance programmes, as studies have shown that families may be FI at this level and may struggle because they do not qualify for food assistance programmes under current guidelines ${ }^{(31)}$. From among 1039 eligible participants, 236 were not invited to participate in the caregiver survey because we had filled their food security group and 259 declined to participate in the survey, leaving 544 caregivers who completed the survey $(52.4 \%)$. The details of the recruitment procedure can be found elsewhere ${ }^{(32)}$. Among these caregivers, 158 were from FS households, 207 were from FI households and 179 were from VLFS-C households. The analysis in the present study included 423 households (128 FS, 158 FI and 137 VLFS-C) with complete data on all variables of interest.

The data were collected from April 2011 through May 2013. Written informed consent was obtained before survey administration. Additional details about the Midlands Family Study and recruitment procedures can be found elsewhere ${ }^{(32)}$. The study protocol was approved by the University of South Carolina Institutional Review Board for the Protection of Human Subjects. 


\section{Measures}

The classification of food security status was based on the Household Food Security Survey Module (HFSSM) ${ }^{(33-35)}$. The HFSSM portion of the screener inquired about eighteen household food insecurity experiences (including eight child-specific items) related to anxiety about food shortages, reduced quality of foods available and reduced quantity of foods available. Households were classified as: FS if they affirmed two or fewer items on the HFSSM; FI if they affirmed three or more items but not five or more child-specific items; or VLFS-C if they affirmed five or more of the eight child-specific items. The coding of food security categories was consistent with a main paper of the study ${ }^{(32)}$.

We included both perceived and GIS-based food environment measures in the current study. Five questions on perceptions of the food environment previously developed for the Multi-Ethnic Study of Atherosclerosis (MESA) Neighborhood Study ${ }^{(36)}$, in addition to one perception question of food affordability, 'Are the fresh fruits and vegetables in your community or neighborhood affordable?', were used to evaluate perceived food environment. Thus, six questions and assessment statements on perceptions of the food environment were used in the present study, including (i) 'How much of a problem would you say that lack of access to adequate food shopping is in your neighborhood?'; (ii) 'A large selection of fresh fruits and vegetables is available in my neighborhood'; (iii) 'The fresh fruits and vegetables in my neighborhood are of high quality'; (iv) 'Are the fresh fruits and vegetables in your community or neighborhood affordable?'; (v) 'A large selection of low-fat products is available in my neighborhood'; and (vi) 'There are many opportunities to purchase fast foods in my neighborhood such as McDonald's, Taco Bell, KFC and takeout pizza places, etc.'. As in other food environment research, the neighbourhood was defined as an area within a 20 -min walk or 1 mile $(1.6 \mathrm{~km})$ from home ${ }^{(27,36)}$. The responses to the above questions in the questionnaire were on a Likert scale ranging from 1 ('strongly agree') to 6 ('strongly disagree') except for question (i), for which the responses ranged from 1 ('very serious problem') to 4 ('not really a problem'). To align the interpretation of responses so that a higher score indicated better food access, the responses were reverse coded for questions (ii), (iii), (iv) and (v) (i.e. responses to opportunities to purchase fast food (vi) and to the overall access question (i) were left as is). The validity and reliability of the MESA questions have been assessed in previous studies showing that the questions are valid and have good internal and test-retest reliability ${ }^{(27,37)}$; however, we used a 6-point response for questions (ii), (iii), (v) and (vi) rather than the 5-point scale from the original MESA questionnaire. The validity and reliability of the revised questionnaire have not been evaluated.

For geographic measures, distance from a participant's home to the nearest supermarket (including grocery stores) was calculated based on the list of supermarkets in the South Carolina Department of Health and Environmental Control food retail licensing database from 20122013. According to our previous validation, this data set is one of the best secondary food outlet data sets in this eight-county area, with a sensitivity (the fraction of open food outlets that were listed and found to be open during the field census) of $68 \%$ and a positive predictive value (the fraction of all listed food outlets that were 'located and open' during the field census) of $89 \%{ }^{(38)}$.

The covariates included: race (White, African American or other); urbanicity (urban or non-urban); number of children in the household (1, 2, 3 or more); number of adults in the household (1, 2, 3 or more); homeless in past year (yes or no); monthly mortgage/rent expenses (\$US); monthly transportation expenses (\$US); monthly utilities expenses (\$US); health-care expenses over \$US 2000 in the past year (yes or no); monthly household wages (\$US); monthly Supplemental Nutrition Assistance Program (SNAP) allotment (\$US); other monthly assistance (\$US); Confusion, Hubbub, and Order Scale (CHAOS, a scale designed to assess the level of confusion and disorganization in the home environment; ranging from 0 to 14); perceived social support (ranging from 3 to 21); negative life events (ranging from 0 to 57); perceived stress (ranging from 0 to 30); and intrinsic religiosity (ranging from 2 to 15). The monetary variables were transformed to be in increments of \$US 100. The variables with outliers and skewed distributions were Winsorized at the 95th percentile to reduce the influence of outliers (e.g. monthly household wages and other monthly assistance) and centred for the analysis.

\section{Statistical analysis}

The network distance (along the road) to the nearest supermarket was calculated in ArcGIS version 10.0 (ESRI, Redlands, CA, USA). Street centrelines from Streetmap Premium (ESRI, 2011) based on commercial street centreline data from NAVTEQ and TomTom were used within the Network Analyst extension of ArcGIS. US Census 2010 boundaries were used in the present study. The distance was log-transformed because of the skewness of the distribution. Multinomial logistic regression models were used to examine the associations between perception measures and GIS distance variables, with food security status as the outcome variable, while controlling for the covariates described above. The FS group was considered the reference group in the models. Considering the potential clustering errors of households in tracts, i.e. households in the same census tract might be correlated in some unknown way (423 households in 115 tracts), and to prevent the standard errors from being too small, clustering in census tracts was adjusted in the models using robust standard errors. The statistical analyses were performed in the statistical software package Stata version 11 using $\alpha$ level of 0.05 for statistical significance. 


\section{Results}

Characteristics of the study households are summarized by food security status in Table 1 . Monthly wages, monthly mortgage/rent expenses, percentage of households with health-care expenses over \$US 2000 in the past year, quality of home environment and social support were lower as food insecurity worsened across the three food security categories, and negative life events and perceived stress levels were higher as food insecurity levels became more severe. Compared with FS households, FI households were less likely to live in an urban area and tended to have higher response scores on the intrinsic religiosity scale, and VLFS-C households were more likely to be African American, live in an urban area, have lower monthly transportation expenses and have been homeless in the past year.

Table 2 summarizes the perceived and GIS-based food environment measures by food security status. Compared with FS households, FI households reported poorer quality of fruits and vegetables in the neighbourhood and reported that food access is a more severe problem in the neighbourhood. Similarly, compared with FS households, VLFS-C households reported lower scores on all other food environment perception items except for opportunities to purchase fast food, indicating that VLFS-C households perceived a much worse neighbourhood food environment than FS households. On average, the GIS-based distance to the nearest supermarket was shorter for VLFS-C households than for FS households.

The results from multinomial logistic regression models adjusting for the key covariates are shown in Table 3. Compared with FS households, VLFS-C households had lower odds of reporting easy access to healthful and adequate food shopping ( $\mathrm{OR}=0.56 ; 95 \%$ CI $0.41,0.75)$. VLFS-C households had a $39 \%$ reduction in the odds of perceiving access to affordable food compared with FS households ( $\mathrm{OR}=0.61 ; 95 \%$ CI 0.50, 0.74). Likewise, compared with FS households, VLFS-C households had lower odds of reporting fruit and vegetable availability $\quad(\mathrm{OR}=0.75 ; \quad 95 \% \quad \mathrm{CI} \quad 0.61,0.92)$, fruit and vegetable quality $(\mathrm{OR}=0.72 ; 95 \% \mathrm{CI} 0.59,0.87)$ and availability of low-fat products in their neighbourhoods $(\mathrm{OR}=0.72 ; 95 \% \mathrm{CI} 0 \cdot 58,0 \cdot 90)$. FI households had lower odds of reporting fewer opportunities to purchase fast food $(\mathrm{OR}=0.81 ; 95 \%$ CI $0.68,0.97)$. No significant differences were found between FI and FS households for other perception items. The network distance to the nearest supermarket was not associated with food security status among children.

Table 1 Characteristics of study households by food security status ( $n$ 423); Midlands Family Study, South Carolina, USA, April 2011May 2013

\begin{tabular}{|c|c|c|c|c|c|c|}
\hline \multirow[b]{2}{*}{ Characteristic } & \multicolumn{2}{|c|}{$\mathrm{FS}(n$ 128) } & \multicolumn{2}{|c|}{$\mathrm{FI}(n 158)$} & \multicolumn{2}{|c|}{ VLFS-C $(n$ 137) } \\
\hline & $\%$ or Mean & SD & $\%$ or Mean & SD & $\%$ or Mean & SD \\
\hline African American (\%) & $68 \cdot 8$ & - & $77 \cdot 2$ & - & $89 \cdot 1$ & - \\
\hline Living in an urban area (\%) & $58 \cdot 6$ & - & $46 \cdot 8$ & - & $70 \cdot 1$ & - \\
\hline \multicolumn{7}{|l|}{ Number of children in the household (\%) } \\
\hline 1 & 34.4 & - & $40 \cdot 5$ & - & $30 \cdot 7$ & - \\
\hline 2 & 35.9 & - & 38.0 & - & 33.6 & - \\
\hline 3 or more & $29 \cdot 7$ & - & 21.5 & - & $35 \cdot 8$ & - \\
\hline \multicolumn{7}{|l|}{ Number of adults in the household (\%) } \\
\hline 1 & 38.3 & - & $46 \cdot 2$ & - & $49 \cdot 6$ & - \\
\hline 2 & $48 \cdot 4$ & - & $36 \cdot 1$ & - & 39.4 & - \\
\hline 3 or more & 13.3 & - & $17 \cdot 7$ & - & $11 \cdot 0$ & - \\
\hline Monthly wages (\$US) & $2226 \cdot 0$ & 2556.8 & $1201 \cdot 0$ & $1390 \cdot 4$ & $786 \cdot 2$ & $903 \cdot 2$ \\
\hline Monthly SNAP allotment (\$US) & 263.1 & $278 \cdot 2$ & $265 \cdot 3$ & $226 \cdot 1$ & $281 \cdot 2$ & $249 \cdot \varepsilon$ \\
\hline Monthly other assistance (\$US) & $426 \cdot 7$ & $742 \cdot 8$ & $500 \cdot 3$ & $1052 \cdot 3$ & 437.2 & 574.2 \\
\hline Monthly mortgage/rent expenses (\$US) & $472 \cdot 2$ & $370 \cdot 8$ & $367 \cdot 6$ & 292.5 & $368 \cdot 4$ & $277 \cdot 9$ \\
\hline Monthly transportation expenses (\$US) & $121 \cdot 0$ & $203 \cdot 6$ & $112 \cdot 9$ & $179 \cdot 0$ & $50 \cdot 7$ & $119 \cdot 4$ \\
\hline Monthly utilities expenses (\$US) & 362.4 & $213 \cdot 8$ & $351 \cdot 3$ & $232 \cdot 6$ & $322 \cdot 7$ & 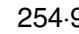 \\
\hline Health-care expenses over \$US 2000 in past year (\%) & $33 \cdot 6$ & - & 21.5 & - & $19 \cdot 7$ & - \\
\hline $\mathrm{CHAOS}^{*}$ & $3 \cdot 1$ & $2 \cdot 8$ & $4 \cdot 2$ & 2.9 & $5 \cdot 5$ & 3.7 \\
\hline Perceived social support† & $17 \cdot 4$ & 3.3 & $15 \cdot 9$ & 3.5 & $14 \cdot 1$ & $4 \cdot 2$ \\
\hline Negative life events $\ddagger$ & 8.9 & $7 \cdot 8$ & 13.9 & $9 \cdot 6$ & $18 \cdot 7$ & $11 \cdot c$ \\
\hline Perceived stress§ & $10 \cdot 8$ & $5 \cdot 6$ & $14 \cdot 3$ & 5.9 & $16 \cdot 1$ & $5 \cdot \varepsilon$ \\
\hline Intrinsic religiosityll & $12 \cdot 5$ & $3 \cdot 1$ & 13.5 & 1.9 & $12 \cdot 9$ & 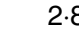 \\
\hline Homeless in the past year (\%) & $21 \cdot 1$ & - & 27.9 & - & $44 \cdot 5$ & - \\
\hline
\end{tabular}

FS, food secure; FI, food insecure; VLFS-C, very low food security among children; SNAP, Supplemental Nutrition Assistance Program; CHAOS, Confusion, Hubbub, and Order Scale.

Bold font indicates that the difference by food security group is significant based on the $t$ test for continuous variables and the $x^{2}$ test for categorical variables $(P<0.05)$.

${ }^{\star}$ Ranges from 0 to 14 , the larger the score, the more chaotic the home environment.

†Ranges from 3 to 21 , the larger the score, the better the social support.

$\ddagger$ Ranges from 0 to 57 , the higher the score, the more negative life events.

§Ranges from 0 to 30 , the larger the score, the more severe the perceived stress.

IRanges from 3 to 15, the larger the score, the more frequent religious activity. 
Table 2 Descriptive statistics on neighbourhood food access measures by household food security status ( $n$ 423); Midlands Family Study, South Carolina, USA, April 2011-May 2013

\begin{tabular}{|c|c|c|c|c|c|c|}
\hline \multirow[b]{2}{*}{ Neighbourhood food access measure } & \multicolumn{2}{|c|}{$\mathrm{FS}(n$ 128) } & \multicolumn{2}{|c|}{$\mathrm{FI}(n 158)$} & \multicolumn{2}{|c|}{ VLFS-C ( $n$ 137) } \\
\hline & Mean & SD & Mean & SD & Mean & SD \\
\hline \multicolumn{7}{|l|}{ Perceptions of neighbourhood food access* } \\
\hline Food access is a problemt & 3.3 & 1.0 & 3.0 & $1 \cdot 0$ & $2 \cdot 5$ & $1 \cdot 1$ \\
\hline Availability of fruits and vegetables $\ddagger$ & 4.3 & 1.8 & 3.9 & 1.8 & $3 \cdot 4$ & 1.9 \\
\hline Quality of fruits and vegetables $\ddagger$ & $4 \cdot 2$ & 1.7 & $3 \cdot 8$ & $1 \cdot 6$ & 3.3 & $1 \cdot 7$ \\
\hline Fruits and vegetables are affordable $\neq$ & 4.3 & 1.5 & 3.9 & 1.6 & $3 \cdot 2$ & 1.6 \\
\hline Availability of low-fat products $\ddagger$ & $4 \cdot 2$ & 1.7 & $3 \cdot 8$ & 1.7 & $3 \cdot 3$ & $1 \cdot 8$ \\
\hline Opportunities to purchase fast food§ & $2 \cdot 7$ & 1.9 & $2 \cdot 4$ & 1.6 & 2.5 & 1.7 \\
\hline \multicolumn{7}{|l|}{ Geographic access to supermarkets } \\
\hline Distance to nearest supermarket (miles) & 1.9 & 1.9 & $2 \cdot 1$ & $2 \cdot 1$ & $1 \cdot 6$ & $1 \cdot 6$ \\
\hline
\end{tabular}

FS, food secure; FI, food insecure; VLFS-C, very low food security among children.

Bold font indicates that the difference by food security group is significant based on the $t$ test for continuous variables $(P<0.05)$.

${ }^{*}$ We coded the responses to all the perception questions in this way: larger value indicates better food access/neighbourhood food environment.

†Larger value indicates less of a food access problem (scale: $1=$ 'very serious problem', 2 = 'somewhat serious problem', $3=$ 'minor problem', $4=$ 'not really a problem').

†Larger value indicates better availability/quality/affordability (scale: 1 = 'strongly disagree', $2=$ 'disagree', $3=$ 'somewhat disagree', $4=$ 'somewhat agree', $5=$ 'agree', $6=$ 'strongly agree').

$\S$ Larger value indicates less opportunities to purchase fast food (scale: $1=$ 'strongly agree', $2=$ 'agree', $3=$ 'somewhat agree', $4=$ 'somewhat disagree', $5=$ 'disagree', $6=$ 'strongly disagree').

Table 3 The associations between neighbourhood food access measures and household food security status ( $n$ 423); Midlands Family Study, South Carolina, USA, April 2011-May 2013

\begin{tabular}{|c|c|c|c|c|c|c|}
\hline \multirow[b]{2}{*}{ Neighbourhood food access measures } & \multicolumn{3}{|c|}{$\mathrm{FI} v . \mathrm{FS}$} & \multicolumn{3}{|c|}{ VLFS-C v. FS } \\
\hline & Adjusted $\mathrm{OR}^{*}$ & $95 \% \mathrm{Cl}$ & $P$ value & Adjusted OR* & $95 \% \mathrm{Cl}$ & $P$ value \\
\hline \multicolumn{7}{|l|}{ Perceptions of neighbourhood food access $†$} \\
\hline Food access is a problem $\ddagger$ & 0.82 & $0.63,1.07$ & 0.145 & 0.56 & $0.41,0.75$ & 0.000 \\
\hline Availability of fruits and vegetables§ & 0.91 & $0.77,1.09$ & 0.317 & 0.75 & $0.61,0.92$ & 0.006 \\
\hline Quality of fruits and vegetables§ & 0.88 & $0.74,1.04$ & 0.157 & 0.72 & $0.59,0.87$ & 0.001 \\
\hline Fruits and vegetables are affordable§ & 0.86 & $0.71,1.02$ & 0.094 & 0.61 & $0.50,0.74$ & 0.000 \\
\hline Availability of low-fat products§ & 0.92 & $0.77,1.11$ & 0.404 & 0.72 & $0.58,0.90$ & 0.004 \\
\hline Opportunities to purchase fast foodll & 0.81 & $0.68,0.97$ & 0.023 & 0.94 & $0.77,1.14$ & 0.508 \\
\hline \multicolumn{7}{|l|}{ Geographic access to supermarkets } \\
\hline Distance to nearest supermarket, logף & 0.98 & $0.72,1.32$ & 0.869 & 0.96 & $0.65,1.41$ & 0.837 \\
\hline
\end{tabular}

FS, food secure; FI, food insecure; VLFS-C, very low food security among children.

*Multinomial logistic regression models were used to examine the association between each access variable and food security status. These models were adjusted for race, urbanicity, number of children in the household, number of adults in the household, homeless in the past year, monthly mortgage/rent expenses, monthly transportation expenses, monthly utilities expenses, health-care expenses over $\$$ US 2000 in the past year, monthly household wages, monthly SNAP (Supplemental Nutrition Assistance Program) allotment, other monthly assistance, CHAOS (CHAOS, Confusion, Hubbub, and Order Scale), perceived social support, negative life events, perceived stress and intrinsic religiosity. For all variables of perceptions of neighbourhood food access, the distance to nearest supermarket (log-transformed) was adjusted in the models.

tWe coded the responses to all the perception questions in this way: larger value indicates better food access/neighbourhood food environment.

†Larger value indicates less of a food access problem (scale: $1=$ 'very serious problem', 2 = 'somewhat serious problem', $3=$ 'minor problem', $4=$ 'not really a problem').

§Larger value indicates better availability/quality/affordability (scale: $1=$ 'strongly disagree', $2=$ 'disagree', $3=$ 'somewhat disagree', $4=$ 'somewhat agree', $5=$ 'agree', $6=$ 'strongly agree').

IILarger value indicates less opportunities to purchase fast food (scale: 1 = 'strongly agree', 2 = 'agree', $3=$ 'somewhat agree', $4=$ 'somewhat disagree', $5=$ 'disagree', $6=$ 'strongly disagree').

IThe variable was log-transformed.

\section{Discussion}

In the present study, we evaluated the associations between varying food security status and perceptions about the nutritional quality of the neighbourhood food environment among households with children. We found that FI households reported more opportunities to purchase fast food than FS households, and VLFS-C households reported substantially poorer perceptions of neighbourhood availability, quality and affordability of fruits and vegetables, and availability of low-fat products, but not opportunities to purchase fast food. We did not find statistically significant differences in GIS-based measures of access to grocery stores and supermarkets by household food security status.

This is one of the first attempts to employ a standard instrument to evaluate perceptions of food environment, especially on the availability, quality and affordability of nutritious foods, among households in different food security groups and examine associations with food security status. Perception is a key element of access ${ }^{(26)}$ and the present study confirmed that perceptions about food 
access are an important factor associated with food security status among households with children. Sharkey et al. ${ }^{(29)}$ evaluated several perception questions on food environment, including the variety of foods available, the availability of grocery stores and the prices of the foods, in their study among Mexican-origin families in Texas border colonias. They found that VLFS-C families reported little variety, few grocery stores and high food prices compared with families without child hunger. However, these differences were not tested with adjustment for covariates in the models ${ }^{(29)}$. Mayer et al. evaluated perceived food access and quality through two simple questions and found that respondents reporting easy access to fruits and vegetables and good quality of neighbourhood grocery stores were less likely to report food insecurity ${ }^{(30)}$. These results are consistent with those in our study. However, Mayer et al. focused only on two simple questions and did not adjust for neighbourhood-level factors during the multivariate analysis. In the present study, we additionally adjusted our multivariate analyses of perceived food environment attributes for GIS-based geographic access to supermarkets and grocery stores (distance to the nearest supermarket/ grocery store) and the significant results remained. In the present study, VLFS-C households (equivalent to the child hunger group in the study by Sharkey et $a l^{(29)}$ ) were less likely than FS households to report that fruits and vegetables were affordable. Previous evidence has indicated that higher overall food prices are associated with increased risk of food insecurity and very low food security among American low-income households with children ${ }^{(17)}$. According to our study, VLFS-C and FI households earned significantly less monthly wages than FS households. FI families identify price as the most salient factor influencing their food-purchasing decisions ${ }^{(39)}$. However, after adjusting for monthly wages, monthly expenses and monthly assistance, the differences in perceptions of food access between VLFS-C and FS households remained significant in our study. In the study by Zenk et al. ${ }^{(40)}$, the authors posited that income may be associated with fruit and vegetable intake in an indirect way through perceptions of available selection and affordability of fruits and vegetables. VLFS-C and FI households have lower income on average than FS households, and they thus might have poorer ratings on perceptions of neighbourhood food access, which in turn results in decreased intake of healthful foods.

In the current study, our initial, GIS-based mapped data suggested that retail outlets for fruits and vegetables may be relatively closer to VLFS-C households, but the difference disappeared after adjustment for covariates. In the studies based on Canadian, UK and Australian households, researchers also reported that FI families lived closer to nutritious food sources and grocery stores $^{(22,41,42)}$. In addition, in our study, the geographic measure of distance to the nearest supermarket was not associated with food security status; and nor were other distance-based access measures such as the food desert definition of the US Department of Agriculture or the healthier retail tracts defined by the Centers for Disease Control and Prevention. Thus our results are consistent with previous findings by Kirkpatrick and Tarasuk, who reported that food security was not associated with proximity to food retail $^{(21)}$.

The inconsistency of significance between perception and GIS-based measures of the food environment in the present study could be explained by different dimensions of the environment being characterized by the instruments ${ }^{(7,27,28,43)}$. Previous studies have indicated that individual perceptions are quite distinct from GIS-based features of the food environment ${ }^{(7,27,28)}$. Subjective reports may provide information about the foods that are actually available and are of interest to residents, characteristics that are not captured by GIS data on the locations of facilities ${ }^{(4)}$, and perception measures cannot be substituted for GIS-based measures or vice versa $^{(43)}$. Subjective concepts of food access perceptions evaluated by subjective and behavioural questions - might be more important than GIS measures in determining food security ${ }^{(45)}$. According to previous findings from our group, residents quite accurately reported the presence (or absence) of certain food outlets and the types of these food outlets in their neighbourhood, suggesting that residents are well aware of their built neighbourhood landscape (i.e. perceptions seemed to be congruent with reality). In addition, subjective reports (i.e. perceived lack of food shopping access, availability, quality and affordability of fruits and vegetables, and availability of low-fat products in the neighbourhood) may provide more information on the foods actually available and of interest to residents, characteristics that are not captured by geographic data ${ }^{(43)}$. Thus, perception measures are more likely to reflect a person's reality and that subjective reality is likely to affect behaviours such as food shopping. It is also possible that the responses to the perception questions in our studies were a reflection not only of the environment but also of the respondent's social position. Researchers have shown that an individual's perception can vary by sociodemographic factors such as age, race, gender, class and others ${ }^{(43,46,47)}$. Another explanation might be social exclusion, which makes respondents feel that they have poor access because of their low purchasing power but in reality do live near supermarkets ${ }^{(41,48)}$. For instance, studies from the UK and Australia found relatively more large supermarkets in deprived than affluent areas and that living in a disadvantaged area did not mean fewer opportunities to purchase fresh fruit and vegetables, and debated that social exclusion might be a reason for this phenomenon ${ }^{(41,42)}$.

The findings should be interpreted with caution in light of several limitations. First, the cross-sectional design precludes inference of a temporal causal relationship between food access measures and food security status, especially for perception measures and food security status. Second, we did not have information on food shopping behaviours of the households (e.g. whether they shopped at the nearest 
grocery store, the kinds of foods they prefer to buy, etc.) or the food prices or foods available in the stores. Third, we included distance to the nearest supermarket as the only geographic access measure. Although this is one of the best access measures on accessibility in the neighbourhood food environment, it might not cover all access characteristics and did not allow for evaluation of access to other types of food outlets. Fourth, the responses on both perceived food access and food security status were from parents rather than children in the households in our study. Previous studies showed that parents and children may not report food security status equivalently and children's self-reported food security status may be more common than their parents' reports $^{(49)}$. In addition, among FI households, children may be successfully shielded by adults from food shortage ${ }^{(50)}$. All these may bias the associations between food access and food security status among households with children in the present study. However, we used child-specific items from the HFSSM questionnaire to define the VLFS-C category (five or more items were affirmed of eight child-specific questions). All these questions were designed for households with children, so we believe they caught somewhat the status of the children. Last, although we included several important covariates in the models, we cannot exclude the possibility of residual confounding. Despite these limitations, the present study is one of the first to examine the association between several dimensions of perceived food access (i.e. availability, quality and affordability of nutritious foods) in the neighbourhood and food security status among households with children. Moreover, we had residential addresses and used a high-quality food environment database as the basis for our GIS measures.

VLFS-C households reported lower ratings on perceptions of access to healthful and affordable foods than FS households. Perceived food access was clearly a problem among VLFS-C households in our study population, but there were no differences in spatial access to supermarkets and grocery stores across food security levels. Further research is needed to understand what determines a person's perception of his/her neighbourhood food environment and how this perception is related to food shopping behaviours and local food prices, as well as food security status. Future policies on improving geographic neighbourhood food access and targeting food security should incorporate local residents' perceptions of their neighbourhood food access, especially households with food insecurity.

\section{Acknowledgements}

Financial support: Funding was provided by a grant from the University of Kentucky Center for Poverty Research (UKCPR) through funding by the US Department of Agriculture, Food and Nutrition Service (contract number AG-3198-B-10-0028) and the Advanced Support Program for Integration of Research Excellence-II (ASPIRE-II) grant from the Office of the Vice President for Research at University of South Carolina. The opinions and conclusions expressed herein are solely those of the authors and should not be construed as representing the opinions or policies of the UKCPR or any agency of the Federal Government. M.P.B. completed this work at the University of South Carolina, Arnold School of Public Health, Department of Health, Promotion, Education, and Behavior. Conflict of interest: None. Authorship: X.M. analysed the data and wrote the manuscript; A.D.L. developed the manuscript idea and reviewed and edited the manuscript draft for content and contributed to the study's design; B.A.B. provided oversight for data analyses, contributed to the study design, and reviewed and edited the manuscript; L.M., J.H., C.D. and M.P.B. reviewed and edited the manuscript; C.D. and M.P.B. collected data; S.J.J. conceptualized and wrote the grant, provided oversight for data collection and reviewed and edited the manuscript. Ethics of buman subject participation: The study was reviewed and approved by the University of South Carolina Institutional Review Board for the Protection of Human Subjects.

\section{References}

1. Coleman-Jensen AJ, Gregory C \& Singh A (2014) Household food security in the United States in 2013. http://www.ers. usda.gov/media/1565410/err173_summary.pdf (accessed March 2015).

2. Sharkey JR, Nalty C, Johnson CM et al. (2012) Children's very low food security is associated with increased dietary intakes in energy, fat, and added sugar among Mexican-origin children (6-11 y) in Texas border Colonias. BMC Pediatr 12, 16.

3. Kaiser LL, Melgar-Quinonez HR, Lamp CL et al. (2002) Food security and nutritional outcomes of preschool-age Mexican-American children. J Am Diet Assoc 102, 924-929.

4. Rosas LG, Harley K, Fernald LC et al. (2009) Dietary associations of household food insecurity among children of Mexican descent: results of a binational study. J Am Diet Assoc 109, 2001-2009.

5. Dave JM, Evans AE, Saunders RP et al. (2009) Associations among food insecurity, acculturation, demographic factors, and fruit and vegetable intake at home in Hispanic children. J Am Diet Assoc 109, 697-701.

6. Morland K, Wing S \& Diez-Roux A (2002) The contextual effect of the local food environment on residents' diets: the atherosclerosis risk in communities study. Am J Public Health 92, 1761-1767.

7. Moore LV, Diez Roux AV, Nettleton JA et al. (2008) Associations of the local food environment with diet quality - a comparison of assessments based on surveys and geographic information systems: the multi-ethnic study of atherosclerosis. Am J Epidemiol 167, 917-924.

8. Franco M, Diez-Roux AV, Nettleton JA et al. (2009) Availability of healthy foods and dietary patterns: the MultiEthnic Study of Atherosclerosis. Am J Clin Nutr 89, 897-904.

9. Pearce J, Hiscock R, Blakely T et al. (2008) The contextual effects of neighbourhood access to supermarkets and convenience stores on individual fruit and vegetable consumption. J Epidemiol Community Health 62, 198-201.

10. Bodor JN, Rose D, Farley TA et al. (2008) Neighbourhood fruit and vegetable availability and consumption: the role of small food stores in an urban environment. Public Health Nutr 11, 413-420. 
11. Sharkey JR, Johnson CM \& Dean WR (2010) Food access and perceptions of the community and household food environment as correlates of fruit and vegetable intake among rural seniors. BMC Geriatr 10, 32.

12. Hanson NI, Neumark-Sztainer D, Eisenberg ME et al. (2005) Associations between parental report of the home food environment and adolescent intakes of fruits, vegetables and dairy foods. Public Health Nutr 8, 77-85.

13. Inglis V, Ball K \& Crawford D (2008) Socioeconomic variations in women's diets: what is the role of perceptions of the local food environment? J Epidemiol Community Health 62, 191-197.

14. Rose D \& Richards R (2004) Food store access and household fruit and vegetable use among participants in the US Food Stamp Program. Public Health Nutr 7, 1081-1088.

15. Liese AD, Weis KE, Pluto D et al. (2007) Food store types, availability, and cost of foods in a rural environment. $J \mathrm{Am}$ Diet Assoc 107, 1916-1923.

16. Drewnowski A \& Darmon N (2005) Food choices and diet costs: an economic analysis. J Nutr 135, 900-904.

17. Zhang Q, Jones S, Ruhm CJ et al. (2013) Higher food prices may threaten food security status among American lowincome households with children. J Nutr 143, 1659-1665.

18. Hill BG, Moloney AG, Mize T et al. (2011) Prevalence and predictors of food insecurity in migrant farmworkers in Georgia. Am J Public Health 101, 831-833.

19. Ver Ploeg M, Breneman V, Farrigan T et al. (2009) Access to affordable and nutritious food: measuring and understanding food deserts and their consequences. Report to Congress. Report no. AP-036. http://www.ers.usda.gov/media/242675/ ap036_1_.pdf (accessed April 2016).

20. Charreire H, Casey R, Salze P et al. (2010) Measuring the food environment using geographical information systems: a methodological review. Public Health Nutr 13, 1773-1785.

21. Kirkpatrick SI \& Tarasuk V (2010) Assessing the relevance of neighbourhood characteristics to the household food security of low-income Toronto families. Public Health Nutr 13, 1139-1148.

22. Sadler RC, Gilliland JA \& Arku G (2013) A food retail-based intervention on food security and consumption. Int $J$ Environ Res Public Health 10, 3325-3346.

23. Carter MA, Dubois L, Tremblay MS et al. (2012) Local social environmental factors are associated with household food insecurity in a longitudinal study of children. BMC Public Health 12, 1038.

24. Nackers LM \& Appelhans BM (2013) Food insecurity is linked to a food environment promoting obesity in households with children. J Nutr Educ Behav 45, 780-784.

25. Broughton MA, Janssen PS, Hertzman C et al. (2006) Predictors and outcomes of household food insecurity among inner city families with preschool children in Vancouver. Can J Public Health 97, 214-216.

26. Usher KM (2015) Valuing all knowledges through an expanded definition of access. J Agric Food Syst Community Dev 5, 109-114.

27. Echeverria SE, Diez-Roux AV \& Link BG (2004) Reliability of self-reported neighborhood characteristics. J Urban Health 81, 682-701.

28. Freedman DA \& Bell BA (2009) Access to healthful foods among an urban food insecure population: perceptions versus reality. J Urban Health 86, 825-838.

29. Sharkey JR, Dean WR \& Nalty CC (2013) Child hunger and the protective effects of Supplemental Nutrition Assistance Program (SNAP) and alternative food sources among Mexican-origin families in Texas border colonias. BMC Pediatr 13, 143.
30. Mayer VL, Hillier A, Bachhuber MA et al. (2014) Food insecurity, neighborhood food access, and food assistance in Philadelphia. J Urban Health 91, 1087-1097.

31. Parrott S, Charite J, Dutta-Gupta I et al. (2013) Comparison of benefits for poor families to middle-class incomes is deeply flawed. http://www.cbpp.org/research/comparisonof-benefits-for-poor-families-to-middle-class-incomes-is-deeplyflawed (accessed September 2015).

32. Liese AD, Draper CL, Martini L et al. (2016) Recruitment strategies and participation in a study of childhood hunger. $J$ Hunger Environ Nutr (In the Press).

33. Guthrie JF \& Nord M (2002) Federal activities to monitor food security. J Am Diet Assoc 102, 904-906.

34. Nord M, Andrews M \& Winicki J (2002) Frequency and duration of food insecurity and hunger in US households. J Nutr Educ Behav 34, 194-200.

35. Nord M \& Hopwood H (2007) Recent advances provide improved tools for measuring children's food security. J Nutr 137, 533-536.

36. Mujahid MS, Diez Roux AV, Morenoff JD et al. (2007) Assessing the measurement properties of neighborhood scales: from psychometrics to ecometrics. Am J Epidemiol 165, 858-867.

37. Ma X, Barnes TL, Freedman DA et al. (2013) Test-retest reliability of a questionnaire measuring perceptions of neighborhood food environment. Health Place 21, 65-69.

38. Liese AD, Colabianchi N, Lamichhane A et al. (2010) Validation of three food outlet databases: completeness and geospatial accuracy in rural and urban food environments. Am J Epidemiol 172, 1324-1333.

39. Dachner N, Ricciuto L, Kirkpatrick SI et al. (2010) Food purchasing and food insecurity among low-income families in Toronto. Can J Diet Pract Res 71, e50-e56.

40. Zenk SN, Schulz AJ, Hollis-Neely T et al. (2005) Fruit and vegetable intake in African Americans: income and store characteristics. Am J Prev Med 29, 1-9.

41. Cummins S \& Macintyre S (1999) The location of food stores in urban areas: a case study in Glasgow. Br Food J 101, 545-553.

42. Winkler E, Turrell G \& Patterson C (2006) Does living in a disadvantaged area mean fewer opportunities to purchase fresh fruit and vegetables in the area? Findings from the Brisbane food study. Health Place 12, 306-319.

43. Barnes TL, Bell BA, Freedman DA et al. (2015) Do people really know what food retailers exist in their neighborhood? Examining GIS-based and perceived presence of retail food outlets in an eight-county region of South Carolina. Spat Spatiotemporal Epidemiol 13, 31-40.

44. Caspi CE, Sorensen G, Subramanian SV et al. (2012) The local food environment and diet: a systematic review. Health Place 18, 1172-1187.

45. Webb P, Coates J, Frongillo EA et al. (2006) Measuring household food insecurity: why it's so important and yet so difficult to do. J Nutr 136, issue 5, 1404S-1408S.

46. Coulton CJ, Korbin J, Chan T et al. (2001) Mapping residents' perceptions of neighborhood boundaries: a methodological note. Am J Community Psychol 29, 371-383.

47. Coulton CJ, Jennings MZ \& Chan T (2013) How big is my neighborhood? Individual and contextual effects on perceptions of neighborhood scale. Am J Community Psychol 51, 140-150.

48. Macintyre S (2007) Deprivation amplification revisited; or, is it always true that poorer places have poorer access to resources for healthy diets and physical activity? Int J Behav Nutr Phys Act 4, 32.

49. Nord M \& Hanson K (2012) Adult caregiver reports of adolescents' food security do not agree well with adolescents' own reports. J Hunger Environ Nutr 7, 363-380.

50. Hanson KL \& Connor LM (2014) Food insecurity and dietary quality in US adults and children: a systematic review. $A m J$ Clin Nutr 100, 684-692. 